\title{
Interaction between simulated dense Scenedesmus dimorphus (Chlorophyta) bloom and freshwater meta-zooplankton community
}

\author{
Zengling MA,${ }^{1,2}$ Hengguo YU, ${ }^{1}$ Ronald W. THRING,${ }^{3}$ Chuanjun DAI, ${ }^{1}$ Anglv SHEN, ${ }^{4}$ Min ZHAO ${ }^{1 *}$ \\ ${ }^{1}$ Zhejiang Provincial Key Laboratory for Subtropical Water Environment and Marine Biological Resources Protection, Wenzhou \\ University, Wenzhou 325035, China; ${ }^{2}$ Center for Marine Bioproducts Development, Flinders University, Adelaide 5001, Australia; \\ ${ }^{3}$ Environmental Science and Engineering, University of Northern British Columbia, Prince George, British Columbia, V2N4Z9 Canada; \\ ${ }^{4}$ Key Laboratory of East China Sea \& Oceanic Fishery Resources Exploitation and Utilization, Ministry of Agriculture P.R. China, East \\ China Sea Fisheries Research Institute, Shanghai 200090, China \\ Corresponding author: zhaomin-zmcn@tom.com
}

\begin{abstract}
Algal bloom has been a subject of much research, especially the occurrence of blue-green algae (cyanobacteria) blooms and their effects on aquatic ecosystems. However, the interaction between green algae blooms and zooplankton community was rarely investigated. In the present study, the effects exerted by Scenedesmus dimorphus (green alga) bloom on the community structure of zooplankton and the top-down control of the bloom process mediated by the zooplankton were evaluated using a series of laboratory cultures. The results showed that a dense $S$. dimorphus bloom could change the zooplankton community structure by decreasing its diversity indices, leading to the enrichment of a particular zooplankton species, Brachionus calyciflorus. In the presence of mixed species of zooplankton, the density of $S$. dimorphus in the culture was decreased as determined by a change in total chlorophyll $a\left(\mathrm{Chl} a\right.$ ) concentration, which was about $200 \mu \mathrm{g} \mathrm{L}^{-1}$ lower than that of the zooplankton-free culture. Furthermore, the number of species belonging to Cladocera, Copepoda and Rotifera all decreased, with all the cladocerans disappeared in the co-culture within 2 weeks of culturing, while the density of rotifers increased from $818( \pm 243)$ ind $\mathrm{L}^{-1}$ at the time of inoculation to $40733( \pm 2173)$ ind $\mathrm{L}^{-1}$ on the $14^{\text {th }}$ day post-inoculation. Grazing of S. dimorphus by the rotifer $B$. calyciflorus neutralized its growth, and the gradual increase in $B$. calyciflorus density eventually led to the collapse of the bloom. Furthermore, grazing by B. calyciflorus also led to a decrease in the maximal photochemical efficiency $\left(\mathrm{F}_{\mathrm{v}} / \mathrm{F}_{\mathrm{m}}\right)$ of photosystem II (PSII). The combined changes occurring in the zooplankton community structure during the process of $S$. dimorphus bloom and the negative effects of grazing on algal growth, morphology and photosynthetic activities confirmed the key role of zooplankton in the control of algal bloom. The results of the study therefore indicated that dense algal blooms caused by non-toxic algae could still remain a threat to aquatic ecosystems.
\end{abstract}

Key words: Algal bloom; Scenedesmus dimorphus; zooplankton; Rotifera; Copepoda; Cladocera; morphology; photochemical efficiency.

Received: December 2017. Accepted: February 2018.

\section{INTRODUCTION}

Aquatic food webs depend on a balance between bottom-up availability of nutrients and top-down control via grazing (Shurin et al., 2012). Phytoplankton blooms usually occur as a result of net biomass production in response to favorable growth conditions and the removal of suppressors (Donaghay et al., 1997; Kang et al., 2015). In China, algal blooms are caused by advanced eutrophication of freshwater lakes, which occur as a result of dramatic increase in nutrient loading and the weak bearing capacity of shallow lakes to nutrient loading (Havens et al., 2001; Paerl and Huisman, 2008; Qin et al., 2010; Xu et al., 2010; Paerl et al., 2011). As a result of reduced light transmission in water, algal bloom can enhance water turbidity, which threatens the survival of benthic algae and aquatic macrophytes (Scheffer et al.,
1997, 2011; Jeppesen et al., 2007). Furthermore, oxygen depletion caused by algal respiration during night time can also lead to the loss of other aquatic organisms (Paerl and Fulton, 2006; Zhang et al., 2011).

Zooplankton constitute an important link in the food web. They feed on the bacteria and algae and become a source of food for aquatic insects and small fish (Turner, 2004, 2014). The community of zooplankton within any natural pond can be very diverse, usually comprising hundreds of protozoa, several rotifers and 10 to 30 microcrustacean species (Norlin et al., 2006; Merrix-Jones et al., 2013). The composition of species within a habitat is influenced by local climate, diurnal cycles, water quality, trophic state, $\mathrm{pH}$, direct predation, food composition (Guisande et al., 2003; Ban et al., 2008; Verschoor et al., 2009; Guo et al., 2011). Moreover, microalgal species and their abundance are directly controlled by zooplankton, 
resulting in complex mutual interactions (Steiner, 2003; Verschoor et al., 2007). Therefore, algal bloom has been suggested to affect the zooplankton community and energy flow in aquatic ecosystems (Gressel et al., 2013; Katsanevakis et al., 2014).

Several studies have reported the decline in abundance of larger-sized zooplankton and increase in abundance of smaller-sized zooplankton following the occurrence of a cyanobacterial bloom, which supplied the toxic food (Hansson et al., 2007; Ke et al., 2008; Deng et al., 2010; Sun et al., 2012). This indicates that the tolerance of zooplankton to algal blooms might be species-dependent, thus the interspecific differences among zooplankton species should also be considered when investigating the interaction between filter feeders and phytoplankton (Tillmanns et al., 2008). However, very few studies have been undertaken to investigate the changes in zooplankton community structure during the process of an algal bloom (Xie et al., 1998; Michaloudi et al., 2009; Gorokhova et al., 2014; Walsh and O'Neil, 2014). This has seriously impeded effort to reveal the relationship between algal bloom and the underlying changes in the community structure of zooplankton.

To our knowledge, no study on the effect of green algae blooms on zooplankton community has been reported. Scenedesmus dimorphus, one of the most common species of freshwater green algae (Trainor, 1992), is commonly observed as colonies in the field, but it often fails to form colonies in long-term axenic cultures (Lürling and Beekman, 1999; Lürling, 2003). Field studies have suggested that Scenedesmus spp. can quickly respond to environmental changes, which explains why Scenedesmus may dominate in turbid and continuous mixed shallow water bodies (Oliver and Ganf, 2000). Furthermore, it grows rapidly and is commonly the dominant species in eutrophic water, making it a likely candidate to give rise to a bloom (Garg and Gard, 2002). The ability of infochemicals released by zooplankton to induce changes in the biochemical composition and morphology of Scenedesmus has been proven (Lürling et al., 1997; Lürling, 2003). In addition, the species-dependent tolerance of zooplankton to algal blooms has been suggested to be an evolutionary mechanism in a natural system that has a long history of algal bloom (Gilbert, 1990; Gustafsson and Hansson, 2004). Zooplankton species that co-exist with dense algal populations may be more able to digest these algae than the species that are mainly found in algal bloom-free water (Sarnelle and Wilson, 2005; Paes et al., 2016). On these bases, we predicted that a dense Scenedesmus bloom could still change the zooplankton community structure by altering the food composition and quality, which would then influence the filter feeding efficiency of zooplankton and can be regarded as a challenge, although Scenedesmus is considered as a non-toxic species. Based on the above hypothesis, the effect of $S$. dimorphus bloom on the community structure of zooplankton over time, and the downward regulation by meta-zooplankton on the growth as well as on the photosynthetic activity of $S$. dimorphus were studied under a series of laboratory experiments.

\section{METHODS}

\section{Organism and culture media}

Scenedesmus dimorphus was isolated from the Wenruitang River (China) in the spring of 2015. Its identification was performed by classical morphological methods. The Wenruitang River is a typical eutrophic urban river, with shallow water and the phytoplankton community in the water is dominated by green algae and diatoms throughout the year (Sun et al., 2018). A single eight-celled colony of $S$. dimorphus approximately $16 \mu \mathrm{m}$ long and $3 \mu \mathrm{m}$ wide was isolated and propagated for all subsequent cultures. Scenedesmus dimorphus was cultured in sterile BG11 medium (Allen and Stanier, 1968) at $25^{\circ} \mathrm{C}$ with light irradiance of $100 \mu \mathrm{mol}$ photons $\mathrm{m}^{-2} \mathrm{~s}^{-1}$ and under a 12:12 $\mathrm{h}$ light-dark regime. The culture was routinely shaken (2-3 times per day) and the cells in the exponential growth phase were harvested and used in the following experiments.

\section{Zooplankton sampling and experiment preparation}

Zooplankton species were collected from the main course of the Wenruitang River that flows through the campus of Wenzhou University in the middle of April 2016. In spring, the chlorophyll $a(\mathrm{Chl} a)$ concentration in the Wenruitang River is around $40 \mu \mathrm{g} \mathrm{L}^{-1}$ and the water temperature is about $25^{\circ} \mathrm{C}$ (Sun et al., 2018). Green algae account for a dominant proportion of the algae in spring and summer (Sun et al., 2018). The total zooplankton species were collected by vertically hauling a net (diameter $20 \mathrm{~cm}$, length $60 \mathrm{~cm}$, and mesh diameter $76 \mu \mathrm{m}$ ) from the bottom to the surface of the river. All samples were immediately removed from the net and temporarily cultured in distilled water inside a 5-L Erlenmeyer flask. A 100-mL sample of the suspension was removed and preserved in formalin followed by staining with Bengal's red for microscopic identification. All the zooplankton members were identified down to the genus or species level, and the average abundance of each species was calculated from three random samples. The zooplankton community structure obtained was used as a control that denoted the zooplankton community before encountering the dense $S$. dimorphus bloom. The remaining zooplankton in the culture were used for subsequent experiments within $2 \mathrm{~h}$. 


\section{S. dimorphus cultured in presence of mixed zooplankton}

The harvested $S$. dimorphus cells were diluted with fresh BG11 medium to yield a Chl $a$ concentration of $47.19( \pm 4.92) \mu \mathrm{g} \mathrm{L}^{-1}$ and cultured in six transparent plastic tanks, each containing $20 \mathrm{~L}$ of culture. The cultures were aerated with ambient air at a flow rate of $500 \mathrm{~mL} \mathrm{~min}^{-1}$ and irradiated with $100 \mu \mathrm{mol}$ photons $\mathrm{m}^{-2} \mathrm{~s}^{-1}$ PAR at $25^{\circ} \mathrm{C}$. Three of the six tanks were kept as controls while the other three tanks were each inoculated with $500 \mathrm{ml}$ of well-mixed zooplankton culture. The 500-mL well-mixed zooplankton culture was first filtered through a nylon net (mesh diameter $76 \mu \mathrm{m}$ ) and the zooplankton retained on the net were then added to the $S$. dimorphus cultures on the $5^{\text {th }}$ day when the Chl $a$ concentration was about 277.21 $( \pm 20.97) \mu \mathrm{g} \mathrm{L}^{-1}$. Both set of cultures were incubated continuously for two weeks. Samples (2-L) of the culture were removed from each tank on the $4^{\text {th }}, 8^{\text {th }}, 12^{\text {th }}$ and $14^{\text {th }}$ days and preserved in formalin for zooplankton identification. At the same time, $2 \mathrm{~mL}$ of the culture was also removed and directly used to determine the concentration of $\mathrm{Chl} a$. Triplicate samples were determined for each treatment, and the data were reported as the mean value and standard deviation for each treatment. The abundance of total zooplankton used in these experiments was slightly higher than the abundance found in the Wenruitang River (Xiao et al., 2012). However, it still had the same order of magnitude, and should therefore reflect the actual zooplankton abundance in the river.

\section{Determination of $\mathrm{Chl} \boldsymbol{a}$ concentration in $S$. dimorphus culture}

In the present study, the Chl $a$ concentration in the $S$. dimorphus culture was determined using a Phyto-PAM Phytoplankton Analyzer (Heinz Walz GmbH, Effeltrich, Germany). In the Phyto-PAM, $\mu$ sec measuring light pulses were generated by an array of light-emitting diodes (LED) featuring 4 different colors: blue $(470 \mathrm{~nm})$, green $(520 \mathrm{~nm})$, light red $(645 \mathrm{~nm})$ and dark red $(665 \mathrm{~nm})$. The different color-measuring light pulses were applied alternately at a high frequency, such that quasi-simultaneous information on Chl fluorescence excited at the four different wavelengths was obtained. This feature is very useful for distinguishing algae with different types of light harvesting pigment antenna (Schreiber, 1994; Ma et al., 2015). Therefore, changes in Chl a concentration in the $S$. dimorphus culture were detected as groups of green algae.

\section{Determination of the biodiversity index of zooplankton community in $S$. dimorphus culture}

To measure the species diversity, we used richness (e.g., the number of species), evenness (the relative abundance distribution of those species) and proportional diversity (a combination of richness and evenness) as defined by the following three indexes: (1) Shannon $H=-\sum\left(n_{i} / N\right) \times \ln \left(n_{i} / N\right)$ (Shannon and Weaver, 1949), (2) Pielou $J=H / \ln S$ (Pielou, 1966), (3) Simpson index $\mathrm{Si}=\sum\left(n_{i} / N\right)^{2}$ (Simpson, 1949), where $H$ and $S$ represent the species diversity index and number of species respectively, $n_{i}$ and $N$ are the number of individuals of the $i$ th species and the total number of individuals, respectively.

\section{Effect of $B$. calyciflorus on $S$. dimorphus culture}

To evaluate the downward regulation of metazooplankton in the process of $S$. dimorphus bloom as well as the photosynthetic activity and cellular phenotype of the bloom-forming species, different amounts of the micro-zooplankton B. calyciflorus Pallas (Rotifera) were added to the $S$. dimorphus cultures followed by incubation in transparent plastic tanks (each containing $10 \mathrm{~L}$ culture). Brachionus calyciflorus from the initial culture sampled from the Wenruitang River was propagated by incubation with the green alga Chlorella vulgaris at a density of about $10^{5}$ cells $\mathrm{L}^{-1}$. The cultures were aerated with ambient air at a flow rate of $500 \mathrm{~mL} \mathrm{~min}^{-1}$ and irradiated with $100 \mu \mathrm{mol}$ photons $\mathrm{m}^{-2} \mathrm{~s}^{-1} \mathrm{PAR}$ at $25^{\circ} \mathrm{C}$. To obtain cultures with increasing abundances of rotifer, different $(200,400,800,1,200$ and 2,000 mL) volumes of a wellmixed culture of high $B$. calyciflorus were filtered through a nylon net (mesh diameter $76 \mu \mathrm{m}$ ) and the retained $B$. calyciflorus cells were inoculated into a $10-\mathrm{L} S$. dimorphus culture. For ease of referencing, inoculums corresponded to 200, 400, 800, 1,200 and 2,000 $\mathrm{mL}$ of $B$. calyciflorus culture were referred to as $1 \mathrm{Z}, 2 \mathrm{Z}, 4 \mathrm{Z}, 6 \mathrm{Z}$ and $10 Z$, respectively, where $1 Z$ was defined as a $B$. calycifloru density of 3344 ind. $\mathrm{L}^{-1}$. Triplicates were conducted at the same time, and the data were reported as the mean value and standard deviation from each treatment.

\section{Photosynthetic activities and morphological examination of $S$. dimorphus}

To evaluate the impacts of zooplankton grazing on the biological response of $S$. dimorphus, the algal cells cocultured with $B$. calyciflorus were sampled at the end of the $1^{\text {st }}, 2^{\text {nd }}$ and $3^{\text {rd }}$ day after $B$. calyciflorus inoculation. The PSII quantum yield of the cells was subsequently determined using a Phyto-PAM (Heinz Walz GmbH, Effeltrich, Germany). To obtain the PSII quantum yield, the minimum fluorescence $\left(\mathrm{F}_{0}\right)$ was initially determined by illuminating the samples with low intensity light $(600$ $\mathrm{Hz}, 665 \mathrm{~nm}, 0.3 \mu \mathrm{mol}$ photons $\mathrm{m}^{-2} \mathrm{~s}^{-1}$ ) after the samples had been kept in the dark for $10 \mathrm{~min}$. Subsequently, the maximal fluorescence $\left(\mathrm{F}_{\mathrm{m}}\right)$ was determined with a $0.8-\mathrm{s}$ pulse of saturating red light of 5,000 $\mu \mathrm{mol}$ photons $\mathrm{m}^{-2} \mathrm{~s}^{-1}$. 
The variable fluorescence $\left(F_{v}\right)$ was defined as $F_{v=} F_{m}-F_{0}$, and the optimal quantum yield was set as $\mathrm{F}_{\mathrm{v}} / \mathrm{F}_{\mathrm{m}}$.

Meanwhile, the morphological changes of $S$. dimorphus were examined with a microscope (Zeiss Axioplan 2; Carl Zeiss, Germany). Digital images were recorded weekly with a Zeiss Axicam HRC color camera (Carl Zeiss, Jena, Germany), and analyzed with a Vision Analysis system (Axio Vision 3.0).

\section{Statistical analysis}

Data from the different measurements were reported as means and standard deviations. One-way ANOVA and Post-hoc tests (Tukey) were used to establish differences among treatments, with a significant level set at 5\% $(\mathrm{P}=0.05)$. Statistical analysis was performed using the SPSS V.16.0 for windows (SPSS inc., Chicago, IL, USA) and all charts were generated using Origin 8.0 (Origin Lab, Northampton, MA, USA).

\section{RESULTS}

\section{Changes in zooplankton community structure during} the $S$. dimorphus culture

Twenty zooplankton species were identified in the mixed zooplankton sample before it was added to the $S$. dimorphus culture. These included 5 Cladocera species, 3 Copepoda species and 12 Rotifera species (Tab. 1). The dominant species were Mesocyclops leuckarti, Asplanchna brightwellii, B. calyciflorus, Keratella valga and Trichocerca cylindrica. However, only three species $(M$. leuckarti, B. calyciflorus and B. urceolaris) survived to the end of the experiment (Tab. 1). The abundances of cladocerans, copepods and rotifers were $180( \pm 59), 437$ $( \pm 82)$ and $818( \pm 243)$ ind. $\mathrm{L}^{-1}$, respectively, at the time of inoculation. All the species belonging to the cladocerans disappeared from the $S$. dimorphus culture at the end of the experiment, but the abundance of rotifer increased to 40733 ( \pm 2173 ) ind. $\mathrm{L}^{-1}$ on the $14^{\text {th }}$ day (Fig. 1a). The total zooplankton abundance in the culture at the time of inoculation consisted of $12.75 \%, 31.05 \%$ and $56.20 \%$ of cladocerans, copepods and rotifers species, respectively. The proportion of cladocerans and copepods decreased with prolonged culturing time, but that of rotifers increased rapidly, reaching $99.68 \%$ of the total zooplankton abundance by the end of the experiment (Fig. 1b).

The species diversity index $(H)$, evenness index $(J)$ and Simpson index $(\mathrm{Si})$ all changed with prolonged culturing time. Increased culturing time and algal cell density resulted in decreased $H$ and $J$ values, which were 3.67 and 0.82 , respectively, at the time of zooplankton inoculation, but decreased to 0.08 and 0.02 on the $14^{\text {th }}$ day

Tab. 1. Changes in abundance of zooplankton species during the emergence and disappearance of S. dimorphus bloom simulated in the laboratory.

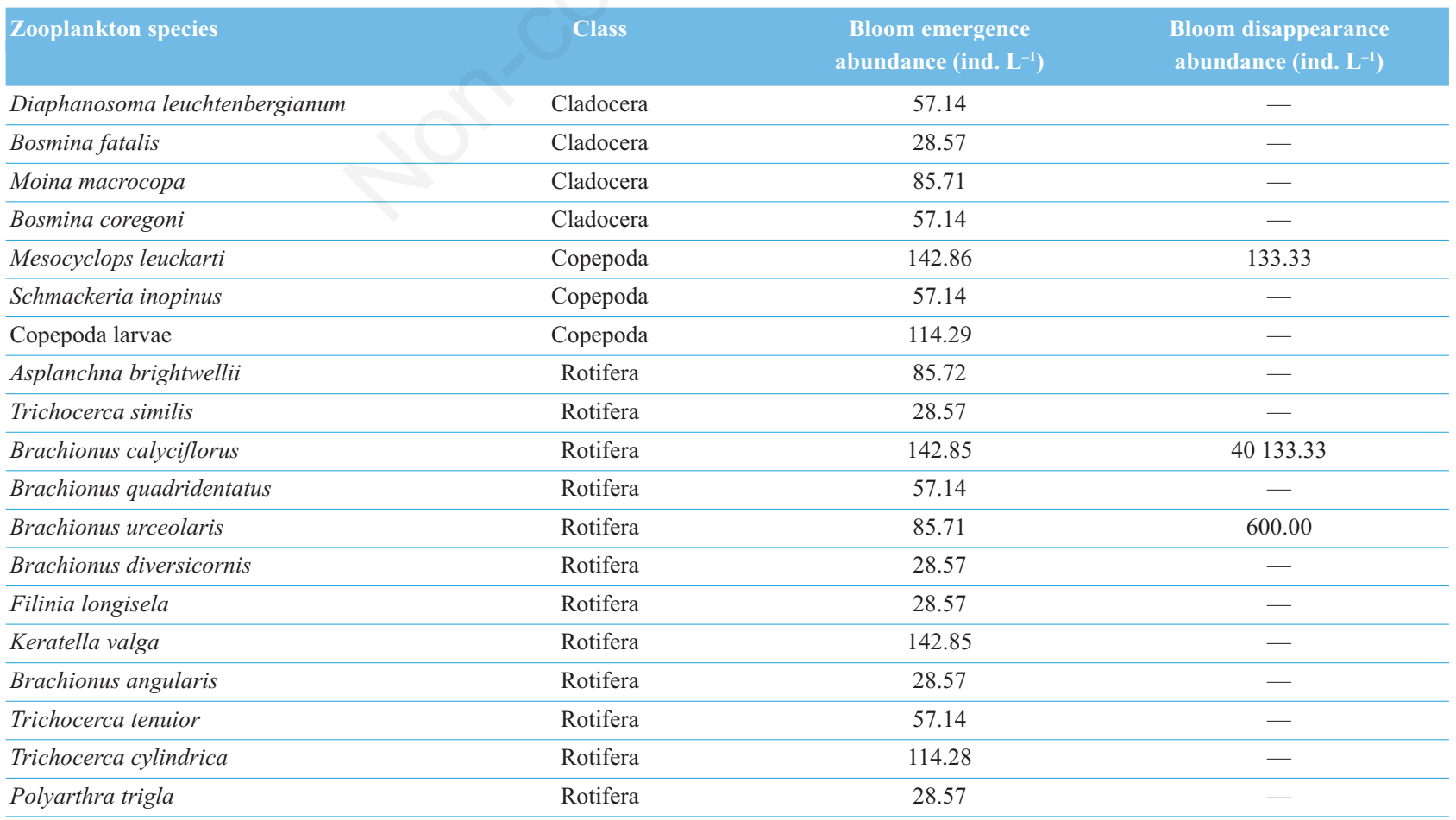


post inoculation. At the same time, the value of $S i$ increased from 0.11 to 0.98 (Tab. 2).

\section{Effects of zooplankton-mediated downward regulation on the dynamics of $S$. dimorphus bloom}

The mean Chl $a$ concentration of the $S$. dimorphus culture increased from $47.19( \pm 4.92) \mu \mathrm{g} \mathrm{L}^{-1}$ at the time of inoculation to $1742.88( \pm 119.89) \mu \mathrm{g} \mathrm{L}^{-1}$ on the $13^{\text {th }}$ day

Tab. 2. Changes in diversity indices of meta-zooplankton community during the emergence and disappearance of $S$. dimorphus bloom simulated in the laboratory.

\begin{tabular}{lccc} 
Time (d) & H & J & Si \\
0 & $3.67 \pm 0.55$ & $0.82 \pm 0.13$ & $0.11 \pm 0.02$ \\
\hline 4 & $2.22 \pm 0.39$ & $0.51 \pm 0.09$ & $0.26 \pm 0.05$ \\
\hline 8 & $1.04 \pm 0.02$ & $0.23 \pm 0.04$ & $0.70 \pm 0.13$ \\
\hline 12 & $0.16 \pm 0.04$ & $0.04 \pm 0.01$ & $0.96 \pm 0.20$ \\
\hline 14 & $0.08 \pm 0.03$ & $0.02 \pm 0.01$ & $0.98 \pm 0.27$
\end{tabular}

Data are the means \pm standard errors obtained from triplicate samples.

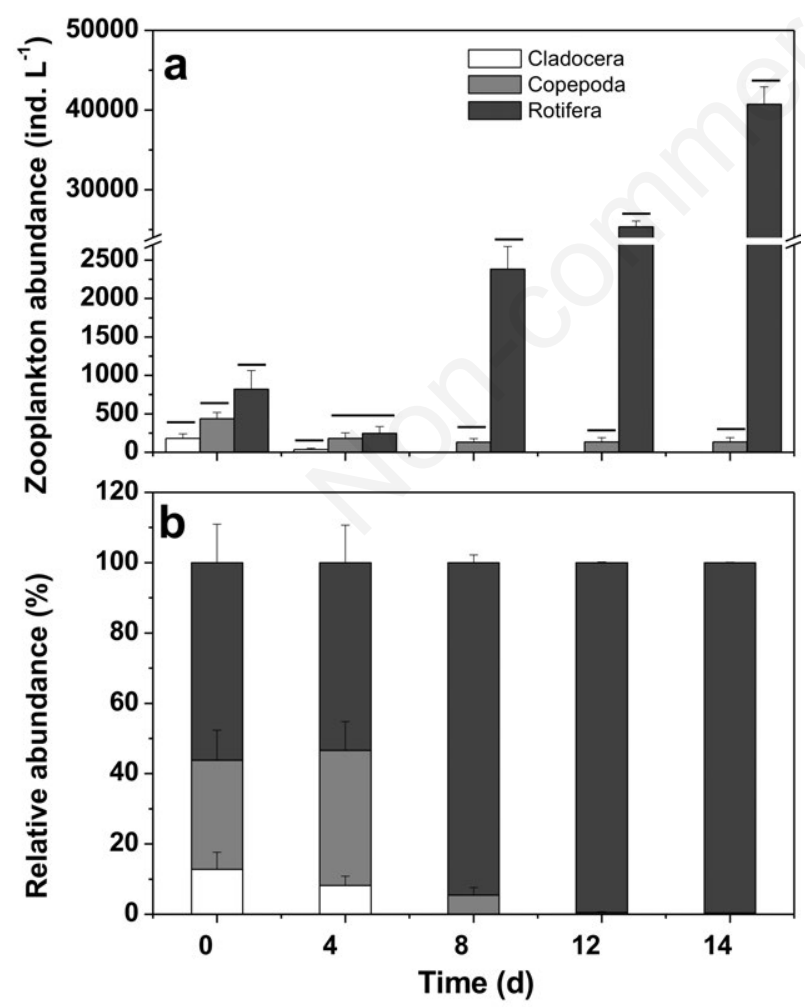

Fig. 1. Changes in zooplankton abundance (a) and relative abundance (b) of meta-zooplankton populations belonging to Cladocera, Copepoda and Rotifera groups during the course of $S$. dimorphus bloom simulated in the laboratory. Data are the means \pm standard deviations obtained from triplicate samples. and then sharply decreased to $64.29( \pm 6.42) \mu \mathrm{g} \mathrm{L}^{-1}$ on the $18^{\text {th }}$ day post-zooplankton inoculation (Fig. 2). The addition of zooplankton did not entirely suppress the continuous development of the algal bloom. However, their presence led to a significant $(\mathrm{P}<0.05)$ decrease in the concentration of $S$. dimorphus cells (represented by reduction in Chl $a$ concentration) and resulted in a faster collapse of the simulated algal bloom. The differences in Chl $a$ concentration over time between the control $S$. dimorphus culture and $S$. dimorphus culture containing the mixed zooplankton ranged from 25.67 to $574.87 \mu \mathrm{g} \mathrm{L}^{-1}$ (average of $253.40 \mu \mathrm{g} \mathrm{L}^{-1}$ ), with the latter having less $\mathrm{Chl}$ $a$ (Fig. 2).

Effect of $B$. calyciflorus abundance on $S$. dimorphus growth and photosynthetic activity

The Chl $a$ concentration of the $S$. dimorphus culture increased with prolonged incubation time (Fig. 3a). However, the growth of $S$. dimorphus was completely neutralized within 2 days when it was inoculated with $1 Z$ of B. calyciflorus (Fig. 3b). In the case of the S. dimorphus culture inoculated with $1 \mathrm{Z} \mathrm{B}$. calyciflorus, the Chl a concentrations were $236.74( \pm 15.63), 237.47( \pm 6.67)$, $238.09( \pm 11.15)$ and $220.34( \pm 13.83) \mu \mathrm{g} \mathrm{L} \mathrm{L}^{-1}$ on days 0,1 , 2 and 3 post- inoculation, respectively. However, when the B. calyciflorus inoculum was increased to $2 \mathrm{Z}, 4 \mathrm{Z}, 6 \mathrm{Z}$ and $10 \mathrm{Z}$, the Chl $a$ concentration decreased to $50.25( \pm 5.77)$, $35.11( \pm 5.37), 31.43( \pm 7.20)$ and $26.22( \pm 4.53) \mu \mathrm{g} \mathrm{L})^{-1}$, respectively, on the $3^{\text {rd }}$ day post-inoculation (Fig. $3 b$ ).

The Chl a concentration of the $S$. dimorphus culture inoculated with $1 \mathrm{Z}$ B. calyciflorus only decreased by $6.9 \%$

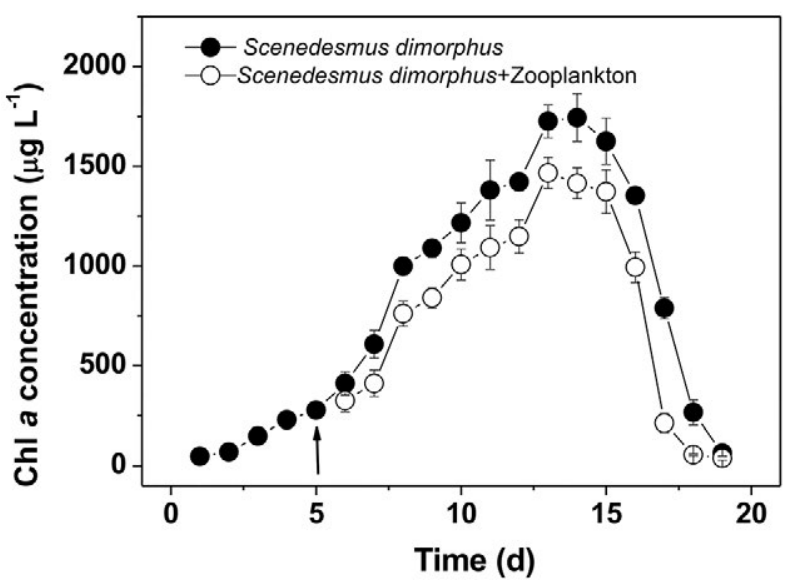

Fig. 2. Changes in Chl a concentration of $S$. dimorphus culture in the absence and presence of mixed meta-zooplankton collected from eutrophic water. Data are the means \pm standard errors obtained from triplicate samples. Arrow indicates the time of zooplankton inoculation. 
in 3 days (Fig. 3b). Therefore, we assumed that the consumption of $S$. dimorphus by $B$. calyciflorus in this case was almost equal to the amount of increase in phytoplankton production. The average specific growth rates $(\mu)$ of the $S$. dimorphus culture were $0.25,0.31$ and $0.34 \mathrm{~d}^{-1}$ on the $1^{\text {st }}, 2^{\text {nd }}$ and $3^{\text {rd }}$ days, respectively, following B. calyciflorus inoculation (Fig. 3A). Thus, if the Chl $a$ concentrations of the culture at the beginning of each day were kept equal to that at the time of inoculation, the corresponding average increase in $\mathrm{Chl} a$ concentration per day should be $65.47,87.53$ and $96.91 \mu \mathrm{g} \mathrm{L}^{-1}$ on day 1 , day 2 and day 3 , respectively, in the absence of B. calyciflorus grazing. This suggested that a biomass corresponding to a Chl $a$ content of 6.20 to 28.98 ng was consumed by one individual B. calyciflorus per day.

The optimal quantum yield $\left(\mathrm{F}_{\mathrm{v}} / \mathrm{F}_{\mathrm{m}}\right)$ of the $S$. dimorphus culture remained stable $(0.67 \pm 0.01)$ during the culturing period. However, in the presence of $B$. calyciflorus, it decreased with increasing zooplankton abundance and prolonged culturing time when the size of the B. calyciflorus inoculum was increased (Fig. 3c). The yield of $S$. dimorphus from cultures inoculated with $1 \mathrm{Z}$, $2 \mathrm{Z}, 4 \mathrm{Z}, 6 \mathrm{Z}$ and $10 \mathrm{Z}$ B. calyciflorus decreased to 0.63 $( \pm 0.01), 0.56( \pm 0.02), 0.52( \pm 0.01), 0.38( \pm 0.02)$ and 0.34 $( \pm 0.02)$, respectively, on the $3^{\text {rd }}$ day post-inoculation. Furthermore, there were significant $(\mathrm{P}<0.05)$ differences among the cultures, except between the culture inoculated with $6 \mathrm{Z}$ and that inoculated with $10 \mathrm{Z}(\mathrm{P}=0.07)$. Within a 3-day period, the abundance of $B$. calyciflorus increased by $215 \%, 195 \%$ and $36 \%$ in the cultures inoculated with $1 \mathrm{Z}, 2 \mathrm{Z}$ and $4 \mathrm{Z}$, respectively. However, for the cultures inoculated with $6 \mathrm{Z}$ and $10 \mathrm{Z}$, the abundance of $B$.
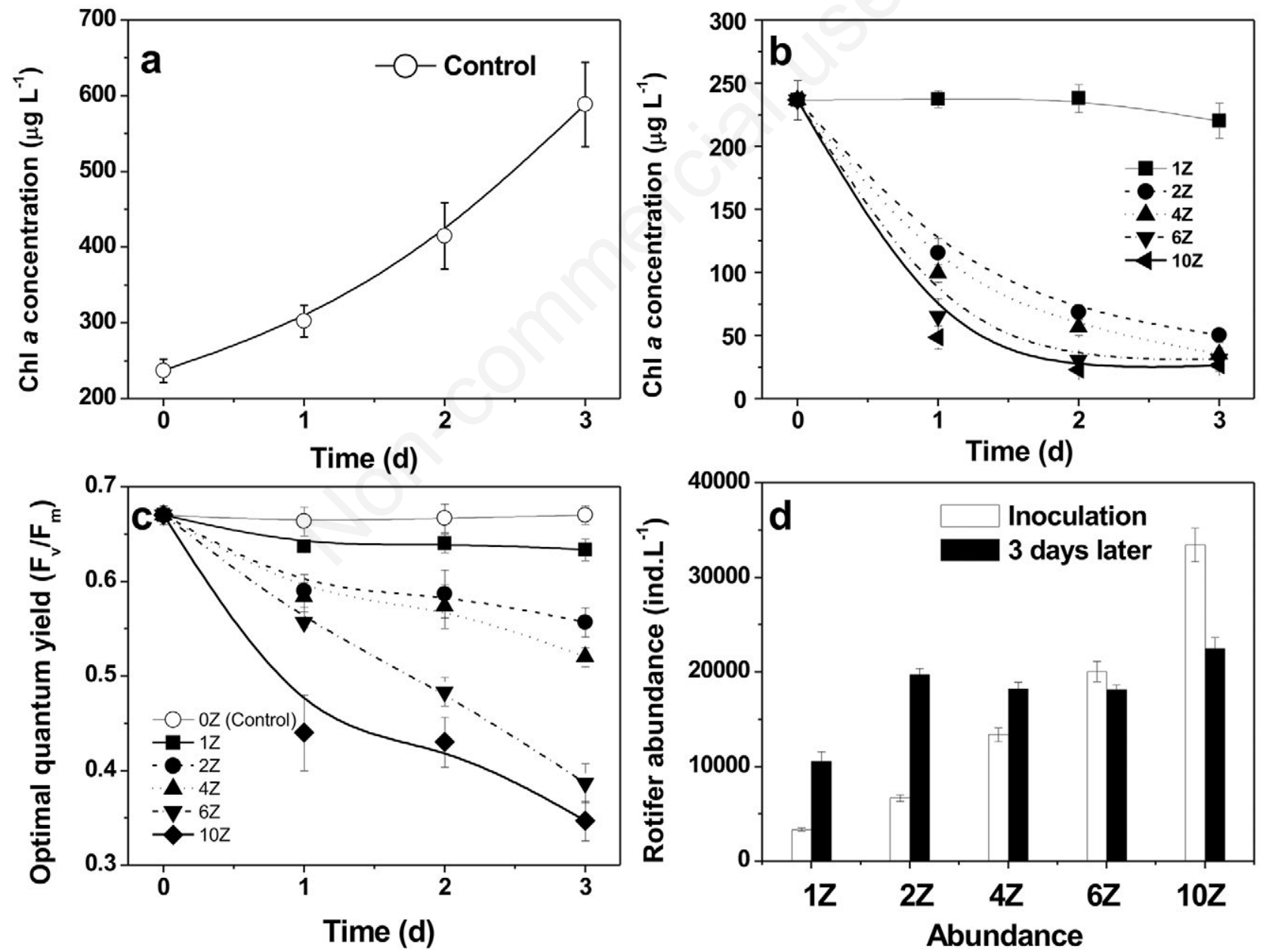

Fig. 3. Changes in Chl $a$ of $S$. dimorphus culture in the absence of rotifer $B$. calyciflorus (a), Chl $a$ (b) and optimal quantum yield $\left(\mathrm{F}_{\mathrm{v}} / \mathrm{F}_{\mathrm{m}}\right)$ of $S$. dimorphus $(\mathrm{c})$ in the presence of different abundance of rotifer B. calyciflorus as well as abundance of B. calyciflorus $(\mathrm{d})$ in the 3-day cultures with the same $\mathrm{Chl}$ a concentration at the time of inoculation. Data are the means \pm standard errors obtained from triplicate samples. 
Calyciflorus decreased by $10 \%$ and $33 \%$, respectively (Fig. 3d).

\section{Effects of $B$. calyciflorus graze on the morphology of $S$. dimorphus}

In addition to the inhibitory effect on the $\mathrm{F}_{\mathrm{v}} / \mathrm{F}_{\mathrm{m}}$ of $S$. dimorphus, grazing by B. calyciflorus also destroyed its single-celled and colony morphologies. Compared to the colonies of $S$. dimorphus cultured in the absence of $B$. calyciflorus (Fig. 4a), the colonies of S. dimorphus from the culture inoculated with $10 \mathrm{Z} \mathrm{B}$. calyciflorus lost their regular conformation, and the cells were damaged and lysed (Fig. 4b). In fact, the damage to algal cells occurred regardless of the abundance of $B$. calyciflorus but was most obvious in the culture containing the highest $B$. calyciflorus abundance (10Z). Furthermore, the damaged cells readily formed flocs and sank to the bottom.

\section{DISCUSSION}

Biodiversity is known to affect the stability and productivity of communities and the trophic interactions among these communities in a natural ecosystem (McArt et al., 2012; Tilman et al., 2014). Our experiments showed that the bloom caused by $S$. dimorphus could decrease the diversity indices of the zooplankton community, while increasing the abundance of one particular species of zooplankton, B. calyciflorus (Tabs. 1 and 2), suggesting that the dense bloom caused by anon-toxic alga could decrease the community stability and lead to the rapid population expansion of the species that could adapt to the bloom more quickly. It should be pointed out that the changes in zooplankton community structure due to algal bloom exposure were assessed by comparing the zooplankton community cultured in the presence of the Scenedesmus bloom to the community initially present in the water sample collected from the river, which was considered as the control. A better control should perhaps consist of the same water sample subjected to the same laboratory culturing conditions and time as the mixed culture, but without the addition of S. dimorphus, since it is well known that some zooplankton species are more difficult to culture than others under laboratory conditions, and some zooplankton species may die because they cannot adapt to the lab culturing conditions. This can also lead to the loss of zooplankton abundance. However, if such a control was included, it would have been necessary to feed the zooplankton with some microalgae species because the population of zooplankton would decline sharply when there is a shortage of food as shown in Fig. 3d. Adding microalgae to the zooplankton culture as food would change the culture condition, making it unsuitable as a control for our purpose. Therefore, the control treatment we used was a realistic and practical choice, though it could not entirely discriminate the impact caused only by the algal bloom from the impact caused by laboratory conditions.

The downward regulation of algal bloom by zooplankton plays an important role in constraining the abundance of phytoplankton in an aquatic ecosystem (Calbet and Landry, 2004; Smayda, 2008), and a lack of control exerted by predators could ultimately lead to a phytoplankton bloom (Irigoien et al., 2005; Modigh and Franzè, 2009). The presence of zooplankton significantly decreased the concentration of $S$. dimorphus cells, thereby
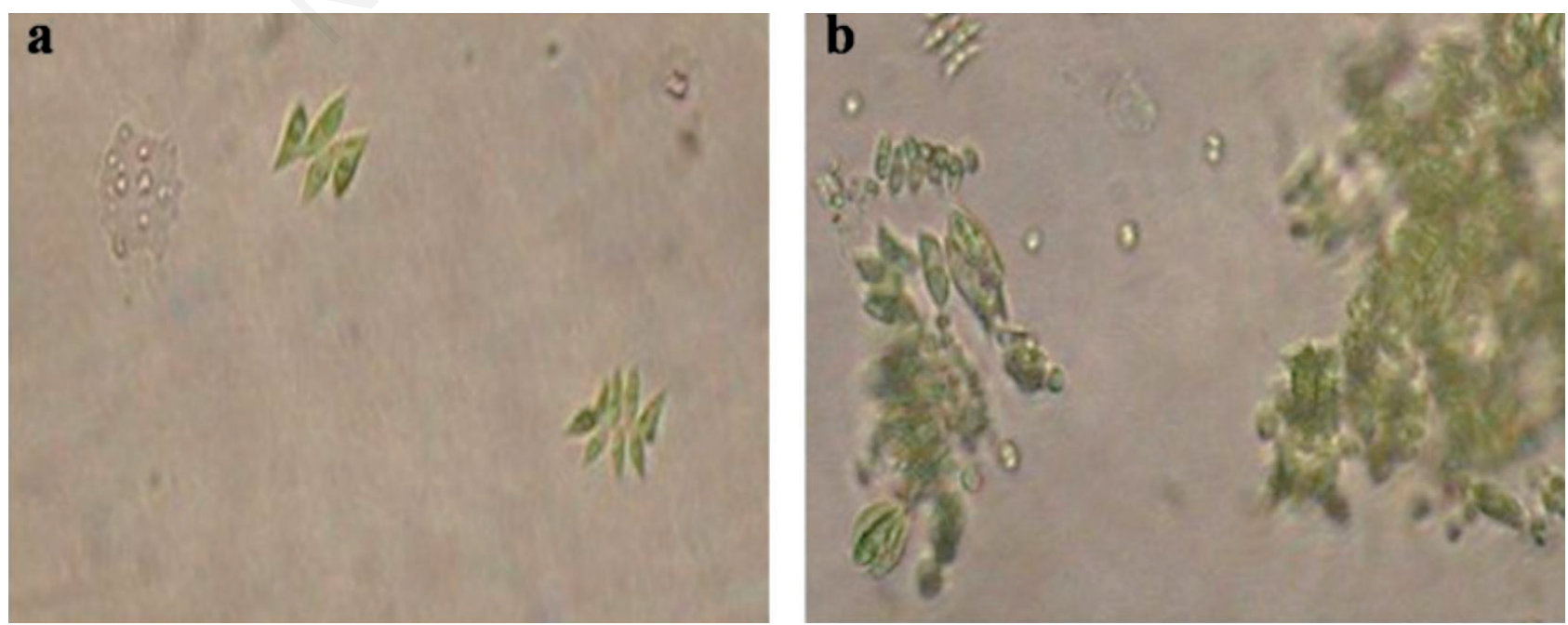

Fig. 4. Morphology of S. dimorphus colonies in the absence (a) and presence (b) of B. calyciflorus in a 3-day culture. 
accelerating the collapse of the bloom (Fig. 2). Furthermore, the bloom caused by $S$. dimorphus was completely constrained by the rotifer $B$. calyciflorus when it was present in sufficiently high abundance (Fig. 3b). Brachionus calyciflorus was not able to fully suppress the algal bloom (Fig. 2), despite reaching a density (up to 40,000 ind. $\mathrm{L}^{-1}$ ) comparable to those used in Fig. 3b, and this might be related to the timing of the inoculation of $B$. calyciflorus (during the initial vs. exponential algal growth phase) besides the much higher concentration of $S$. dimorphus before the inoculation of $B$. calyciflorus (Fig. 2). Rotifers are small zooplankton, usually less than $200 \mu \mathrm{m}$ in size, and they are often the most abundant organisms in highly eutrophic freshwater bodies, having a density between 1000 and 500,000 ind.L $\mathrm{L}^{-1}$ (Roche, 1995; Sarma et al., 2003). Rotifers usually feed on small organisms with diameter of $20 \mu \mathrm{m}$ or less (Pourriot, 1977; Riemann and Ahlrichs, 2008). Brachionus calyciflorus feeds on organisms having a wide range of cell sizes but has a clear preference for the large algae such as Cyclotella sp. and Scenedesmus opoliensis, which have particle size between 10 and $33 \mu \mathrm{m}$ (Pagano, 2008). In natural water, $S$. dimorphus usually exists as colonies of the four- and eight-celled stages (Hessen and Van Donk, 1993) as shown in Fig. 4a, making it an ideal food for $B$. calyciflorus.

In general, cyanobacteria can cause the rapid decrease of large crustaceans because they can interfere with the filter feeding behavior of these animals (Chow-Fraser, 1986; DeMott, 1999). The toxins produced by the cyanobacteria may also be lethal to the crustaceans (DeMott, 1999; Carmichael, 2001; Ke et al., 2008). In addition, the diversity of phytoplankton is thought to be one of the main factors determining the seasonal succession of crustacean zooplankton (Abrantes et al., 2006). Other noticeable features of our experiment were a reduced number of Cladocera, Copepoda and Rotifera species and the complete disappearance of cladocerns at the end of the S. dimorphus bloom. However, the abundance of rotifers increased sharply at the end of the S. dimorphus bloom, reaching almost 50 times the amount present at inoculation (Fig. 1a). The disappearance of most copepods and all cladocerans allowed the rotifers to become the absolute dominant thriving species in the presence of S. dimorphus bloom (Fig. 1b). In addition to the decreased cladocerans and copepods abundance and biodiversity index (Fig. 1a, Tab. 2), the increased growth of B. calyciflorus (Fig. 1 a,b) suggested that $S$. dimorphus bloom might have detrimental effects on the zooplankton community and the response of zooplankton to the bloom appeared to be speciesdependent. Therefore, the zooplankton species that could not adapt to the experimental conditions had probably died out in a short time, reducing the biodiversity indices of the zooplankton population (Tab. 2).
Micro-zooplankton grazing can account for more than half of the phytoplankton production in the coastal and estuarine systems (Calbet and Landry, 2004) and their preferential predation plays a key role in altering the composition of the phytoplankton communities (Strom, 2008). In this study, the growth of $S$. dimorphus was completely neutralized by $B$. calyciflorus grazing and even collapsed when the inoculum of $B$. calyciflorus reached a certain concentration (Fig. 3b). In addition, the abundance of $B$. calyciflorus also increased in the mixed culture (Fig. 3c). Although there are many mechanisms that may result in the loss of phytoplankton, zooplankton grazing and trophic interactions among the zooplankton are widely considered to be the major biological factors influencing the top-down control throughout the development of an algal bloom (Turner, 2004; Irigoien et al., 2005; Smayda, 2008). The balance between phytoplankton growth and total grazing pressure is regarded as the factor that determines the magnitude and duration of the bloom (Turner, 2004, 2014; Smayda, 2008). However, this balance does vary spatially and temporally as specific growth and grazing rates may vary with nutrient condition as well as grazer community composition and abundance. The decline in phytoplankton population inflicted by zooplankton grazing had the potential to suppress bloom development when the grazers were present in high abundance. This could both regulate the bloom magnitude and contribute to the rapid population decline, and the eventual collapse of the bloom (Fig. 2).

Decreases in zooplankton diversity and community composition (Fig. 1, Tab. 2) may have numerous negative consequences for the ecosystem, including a reduction in the net energy transfer to higher trophic levels (Sunda et al., 2006, 2012) and in the efficiency of energy fluxes through the food webs. The flow of water in the Wenruitang River is very slow and the water is often in a stagnant state. The annual concentration of total nitrogen (TN) ranges from $5.33( \pm 0.81)$ to $9.40( \pm 1.25) \mathrm{mg} \mathrm{L}^{-1}$ and that of total phosphorus (TP) ranges from $0.32( \pm 0.18)$ to $0.95( \pm 0.25) \mathrm{mg} \mathrm{L}^{-1}$, both of which are considered as hypereutrophic level (Sun et al., 2018). Scenedesmus dimorphus is also the dominant species in other eutrophic freshwater rivers besides the Wenruitang River, and it can be used as an indicator of water quality (Trainor, 1992; Jafari and Gunale, 2006; Sun et al., 2018). Under suitable conditions, the occurrence of dense S. dimorphus blooms in hypereutrophic rivers can be expected. Therefore, the changes in zooplankton population observed in this study should be applicable to natural environments, although the bloom was stimulated in a capacity-limited container.

Grazing pressure has been associated with changes in productivity, colony size and biomass settleability (Xie et al., 1998; Michaloudi et al., 2009; Gorokhova et al., 2014; 
Walsh and O'Neil, 2014; Montemezzani et al., 2016). Grazing of $S$. dimorphus by B. calyciflorus was found to decrease the yield of S. dimorphus (Fig. 3c) and destroy its regular colony morphology (Fig. 4 a,b). Therefore, it is reasonable to assume that decreases in algal cell density, photosynthetic activity and morphology were caused by the strong grazing pressure exerted by the zooplankton. The results also indicated that the occurrence of $S$. dimorphus bloom might have detrimental effects on the structure of zooplankton community, but could be favorable to some rotifer species such as B. calyciflorus due to the provision of adequate food supply throughout the bloom.

\section{CONCLUSIONS}

Dense bloom of the green alga $S$. dimorphus could decrease the diversity indices of the zooplankton community, leading to increased growth of the rotifer $B$. calyciflorus. Increase in $S$. dimorphus biomass production could be neutralized by $B$. calyciflorus when present in adequate amount. In addition, grazing by $B$. calyciflorus also impaired the cellular structure of $S$. dimorphus and led to decreased $\mathrm{F}_{\mathrm{v}} / \mathrm{F}_{\mathrm{m}}$ ratio. The results indicated that the dense bloom caused by non-toxic algae could be lethal to the zooplankton species that could not adapt to the environmental changes, while enabling the rapid expansion of the population of certain species that could quickly adapt to the bloom conditions. Decrease in the biodiversity of zooplankton community at the end of the $S$. dimorphus bloom indicated that dense non-toxic algal bloom still remains a threat to aquatic ecosystems.

\section{ACKNOWLEDGMENTS}

This study was largely supported by the National Natural Science Foundation (No. 31370381; 31570364), Project of Science and Technology Department (Zhejiang Province) (No. 2015C33246), Key Laboratory of East China Sea \& Oceanic Fishery Resources Exploitation and Utilization, Ministry of Agriculture, P. R. China (No. 2015K03) and Key Laboratory of East China Sea \& Oceanic Fishery Resources Exploitation and Utilization, Ministry of Agriculture, P. R. China (No. 2015K03), and Laboratory of Marine Ecosystem and Biogeochemistry (No. LMEB201706). We sincerely thank Dr Alan K Chang (Wenzhou University) for revising the language of the manuscript, and the anonymous reviewers for their very useful and insightful comments.

\section{REFERENCES}

Abrantes N, Antunes SC, Pereira MJ, Gonçalves F, 2006. Seasonal succession of cladocerans and phytoplankton and their interaction in a shallow eutrophic lake (Lake Vela, Portugal). Acta Oecol. 29:54-64.

Allen MM, Stanier RY, 1968. Selective isolation of blue-green algae from water and soil. J. Gen. Microbiol. 51:203-209.

Ban S, Ohnishi T, Mori T, Lee HW, 2008. Is the negative effect of crowding on ingestion rate in Daphnia pulex induced physically or chemically? Limnology 9:13-18.

Calbet A, Landry MR, 2004. Phytoplankton growth, microzooplankton grazing, and carbon cycling in marine systems. Limnol. Oceanogr. 49:51-57.

Carmichael WW, 2001. Health effects of toxin-producing cyanobacteria: "the CyanoHABs". Hum. Ecol. Risk Assess. 7:1393-1407.

DeMott WR, 1999. Foraging strategies and growth inhibition in five daphnids feeding on mixture of a toxic cyanobacterium and green alga. Freshwater Biol. 42:263-274.

Chow-Fraser P, 1986. An empirical model to predict in situ grazing rate of Diaptomus minutus Lilljeborg on small algal particles. Can. J. Fish. Aquat. Sci. 43:1065-1070.

Deng D, Zhang S, Li Y, Meng X, Yang W, Li Y, Li X, 2010. Effects of Microcystis aeruginosa on population dynamics and sexual reproduction in two Daphnia species. J. Plankton Res. 32:1385-1392.

Donaghay PL, Osborn TR, 1997. Toward a theory of biologicalphysical control of harmful algal bloom dynamics and impacts. Limnol. Oceanogr. 42:1283-1296.

Garg J, Gard HK, 2002. Nutrient loading and its consequences in a lake ecosystem. Trop. Ecol. 43:355-358.

Gilbert JJ, 1990. Why do cladocerans fail to control algal blooms? Hydrobiologia 200:83-97.

Gorokhova E, Hajdu S, Larsson U, 2014. Responses of phytoand zooplankton communities to Prymnesium polylepis (Prymnesiales) bloom in the Baltic Sea. PLoS One 9:e112985.

Gressel J, van der Vlugt CJB, Bergmans HEN, 2013. Environmental risks of large scale cultivation of microalgae: mitigation of spills. Algal Res. 2:286-298.

Guisande C, Bartumeus F, Ventura M, Catalan J, 2003. Role of food partitioning in structuring the zooplankton community in mountain lakes. Oecologia 136:627-634.

Guo R, Snell TW, Yang J, 2011. Ecological strategy of rotifer (Brachionus calyciflorus) exposed to predator- and competitor-conditioned media. Hydrobiologia 658:163-171.

Gustafsson S, Hansson LA, 2004. Development of tolerance against toxic cyanobacteria in Daphnia. Aquat. Ecol. 38:37-44.

Hansson L-A, Gustafsson S, Rengefors K, Bomark L, 2007. Cyanobacterial chemical warfare affects zooplankton composition. Freshwater Biol. 52:1290-1301.

Havens KE, Fukushima T, Xie P, Iwakuma T, James RT, Takamura N, Hanazato T, Yamamoto T, 2001. Nutrient dynamics and the eutrophication of shallow lakes Kasumigaura (Japan), Donghu (PR China), and Okeechobee (USA). Environ. Pollut. 111:262-272.

Hessen DO, Van Donk E, 1993. Morpholigical changes in Scenedesmus induced by substances released from Daphnia. Arch. Hydrobiol. 127:129-140.

Irigoien X, Flynn KJ, Harris RP, 2005. Phytoplankton blooms: A 'loophole' in microzooplankton grazing impact? J. Plankton Res. 27:313-321. 
Jafari NG, Gunale VR, 2006. Hydrobiological study of algae of an urban freshwater river. J. Appl. Sci. Environ. Mgt. 10:153-158.

Jeppesen E, Søndergaard M, Meerhoff M, Lauridsen TL, Jensen JP, 2007. Shallow lake restoration by nutrient loading reduction - some recent findings and challenges ahead. Hydrobiologia 584:239-252.

Kang Y, Koch F, Gobler CJ, 2015. The interactive roles of nutrient loading and zooplankton grazing in facilitating the expansion of harmful algal blooms caused by the pelagophyte, Aureoumbra lagunensis, to the Indian River Lagoon, FL, USA. Harmful Algae 49:162-173.

Katsanevakis S, Wallentinus I, Zenetos A, Leppäkoski E, Çinar ME, Oztürk B, Grabowski M, Golani D, Cardoso AC. 2014. Impacts of invasive alien marine species on ecosystem services and biodiversity: a pan-European review. Aquat. Invasions 9: 91-423.

Ke Z, Xie P, Guo L. 2008. Controlling factors of spring-summer phytoplankton succession in Lake Taihu (Meiliang Bay, China). Hydrobiologia 607:41-49.

Lürling M, 2003. Phenotypic plasticity in the green algae Desmodesmus and Scenedesmus with special reference to the induction of defensive morphology. Ann. Limnol. - Int. J. Lim. 39:85-101.

Lürling M, Beekman W, 1999. Grazer-induced defenses in Scenedesmus (Chlorococcales; Chlorophyceae): coenobium and spine formation. Phycologia 38:368-376.

Lürling M, de Lange HJ, van Donk E, 1997. Changes in food quality of the green alga Scenedesmus induced by Daphnia infochemicals: biochemical composition and morphology. Freshwater Biol. 38:619-628.

Ma Z, Fang T, Thring R W, Li Y, Yu H, Zhou Q, Zhao M, 2015. Toxic and non-toxic strains of Microcystis aeruginosa induce temperature dependent allelopathy toward growth and photosynthesis of Chlorella vulgaris. Harmful Algae 48:21-29.

McArt SH, Cook-Patton SC, Thaler JS, 2012. Relationships between arthropod richness, evenness, and diversity are altered by complementarity among plant genotypes. Oecologia 168:1013-1021.

Merrix-Jones FL, Thackeray SJ, Ormerod SJ, 2013. A global analysis of zooplankton in natural and artificial fresh waters. J. Limnol. 72:140-153.

Michaloudi E, Moustaka-Gouni M, Gkelis S, Pantelidakis K, 2009. Plankton community structure during an ecosystem disruptive algal bloom of Prymnesium parvum. J. Plankton Res. 31:301-309.

Modigh M, Franzè G, 2009. Changes in phytoplankton and microzooplankton populations during grazing experiments at a Mediterranean coastal site. J. Plankton Res. 31:853-864.

Montemezzani V, Duggan IC, Hogg ID, Craggs RJ, 2016. Zooplankton community influence on seasonal performance and microalgal dominance in wastewater treatment High Rate Algal Ponds. Algal Res. 17:168-184.

Norlin JI, Bayley SE, Ross LCM, 2006. Zooplankton composition and ecology in western boreal shallow-water wetlands. Hydrobiologia 560: 97-215.

Oliver RL, Ganf GG, 2000. Freshwater blooms, p. 149-194 In: B.A. Whitton and M. Potts (eds.), The ecology of cyanobacteria. Kluwer, Dortrecht.
Paes TASV, Costa IAS, Silva APC, Eskinazi-Sant' Anna EM, 2016. Can microcystins affect zooplankton structure community in tropical eutrophic reservoirs? Braz. J. Biol. 76: $50-460$.

Paerl HW, Fulton RS III, 2006. Ecology of harmful cyanobacteria, p. 95-107. In: E. Graneli and J. Turner (eds.), Ecology of harmful marine algae. Springer, Berlin.

Paerl HW, Hall NS, Calandrino ES, 2011. Controlling harmful cyanobacterial blooms in a world experiencing anthropogenic and climatic-induced change. Sci. Total Environ. 409:1739-1745.

Paerl H W, Huisman J, 2008. Blooms like it hot. Science 320:57-58.

Pagano M, 2008. Feeding of tropical cladocerans (Moina micrura, Diaphanosoma excisum) and rotifer (Brachionus calyciflorus) on natural phytoplankton: effect of phytoplankton size-structure. J. Plankton Res. 30:401-414.

Pielou EC, 1966. Species-diversity and pattern-diversity in the study of ecological succession. J. Theor. Biol. 10: 70-383.

Pourriot R, 1977. Food and feeding habits of the Rotifera. Arch. Hydrobiol. Beih. 8: 243-260.

Qin B, Zhu G, Gao G, Zhang Y, Li W, Paerl HW, Carmichael WW, 2010. A drinking water crisis in Lake Taihu, China: linkage to climatic variability and lake management. Environ. Manag. 45:105-12.

Riemann O, Ahlrichs WH, 2008. Ultrastructure and function of the mastax in Dicranophorus forcipatus (Rotifera: Monogononta). J. Morphol. 269:698-712.

Roche K, 1995. Growth of the rotifer Brachionus calyciflorus pallas in dairy waste stabilization ponds. Water Res. 29 2255-2260.

Sarma S S S, Trujillo-Hernandez H E, Nandini S, 2003. Population growth of herbivorous rotifers and their predator (Asplanchna) on urban wastewaters. Aquat. Ecol. 37:243-250.

Sarnelle O, Wilson AE, 2005. Local adaptation of Daphnia pulicaria to toxic cyanobacteria. Limnol. Oceanogr. 34:673687.

Scheffer M, Carpenter S, Foley JA, Folke C, Walker B, 2001. Catastrophic shifts in ecosystems. Nature 413:591-596.

Scheffer M, Rinaldi S, Gragnani A, Mur LR, van Nes EH, 1997. On the dominance of filamentous cyanobacteria in shallow, turbid lakes. Ecology 78:272-282.

Schreiber U, 1994. New emitter-detector-cuvette assembly for measuring modulated chlorophyll fluorescence of highly diluted suspension in conjunction with the standard PAM fluorometer. Z. Naturforsch C. 49:646-656.

Shannon CE, Weaver W, 1949. The mathematical theory of communication. University of Illinois Press, Urbana: $117 \mathrm{pp}$.

Shurin JB, Clasen JL, Greig HS, Kratina P, Thompson PL, 2012. Warming shifts top-down and bottom-up control of pond food web structure and function. Philos. T.R. Soc. B. 367:3008-3017.

Simpson EH, 1949. Measurement of diversity. Nature 163:688.

Smayda TJ, 2008. Complexity in the eutrophication-harmful algal bloom relationship, with comment on the importance of grazing. Harmful Algae 8:140-151.

Steiner CF, 2003. Keystone predator effects and grazer control of planktonic primary production. Oikos 101:569-577.

Strom S L, 2008. Microbial ecology of ocean biogeochemistry: a community perspective. Science 320: 043-1045. 
Sun X, Tao M, Qin B, Qi M, Niu Y, Zhang J, Ma Z, Xie P, 2012. Large-scale field evidence on the enhancement of smallsized cladocerans by Microcystis blooms in Lake Taihu, China. J. Plankton Res. 34: 853-863.

Sun Y, Yu H, Zhou Q, Liu T, Li Y, Ma Z, (2018). [Phytoplankton community types and seasonal variation in Wenruitang River, atypical eutrophic urban river].[Article in Chinese with English abstract]. J. Lake Sci. (in press).

Sunda WG, Graneli E, Gobler CJ, 2006. Positive feedback and the development and persistence of ecosystem disruptive algal blooms. J. Phycol. 42: 963-974.

Sunda WG, Shertzer KW, 2012. Modeling ecosystem disruptive algal blooms: positive feedback mechanisms. Mar. Ecol. Prog. Ser. 447:31-47.

Tillmanns AR, Wilson AE, Pick FR, Sarnelle O, 2008. Metaanalysis of cyanobacterial effects on zooplankton population growth rate: species specific responses. Fund. Appl. Limnol. 171:285-295.

Tilman D, Isbell F, Cowles JM, 2014. Biodiversity and ecosystem functioning. Annu. Rev. Ecol. Evol. Syst. 45:471-93.

Trainor FR, 1992. Cyclomorphosis in Scenedesmus armatus (Chlorophyceae): an ordered sequence of ecomorphos development. J. Phycol. 28:553-558.

Turner JT, 2004. The importance of small planktonic copepods and their roles in pelagic marine food webs. Zool. Stud. 43:255-266.

Turner JT. 2014. Planktonic marine copepods and harmful algae. Harmful Algae 32:81-93.
Verschoor AM, Bekmezci OK, Van Donk E, Vijverberg J, 2009. The ghost of herbivory past: slow defence relaxation in the chlorophyte Scenedesmus obliquus. J. Limnol. 68:327-335.

Verschoor AM, Zadereev YS, Mooij WM, 2007. Infochemicalmediated trophic interactions between the rotifer Brachionus calyciflorus and its food algae. Limnol. Oceanogr. 52:21092119.

Walsh BM, O’Neil JM, 2014. Zooplankton community composition and copepod grazing on the West Florida Shelf in relation to blooms of Karenia brevis. Harmful Algae 38:63-72.

Xiao B, Sun L, Feng D, Yu N, Chen L, 2012. [Meta-zooplankton community structure and its relationship with environmental factors in Wenruitang River].[Article in Chinese with English abstract]. J. Hydroecology 33:14-20.

Xie P, Iwakuma T, Fujii K, 1998. Changes in the structure of a zooplankton community during a Ceratium (dinoglagellate) bloom in a eutrophic fishless pond. J. Plankton Res. 22:1663-1678

Xu H, Paerl H W, Qin B, Zhu G, Gao G, 2010. Nitrogen and phosphorus inputs control phytoplankton growth in eutrophic Lake Taihu, China. Limnol. Oceanogr. 55:420432

Zhang M, Wang Z, Xu J, Liu Y, Ni L, Cao T, Xie P, 2011. Ammonium, microcystins, and hypoxia of blooms in eutrophic water cause oxidative stress and $\mathrm{C}-\mathrm{N}$ imbalance in submersed and floating-leaved aquatic plants in Lake Taihu, China. Chemosphere 82:329-339. 